\title{
Child Poverty, Investment in Children and Generational Mobility: The Short and Long Term Wellbeing of Children in Urban China after the One Child Policy
}

\author{
Gordon Anderson and Teng Wah Leo
}

October 2008

Many thanks for helpful comments are due to seminar participants at the 2007 meetings of the Canadian Economics Association, Halifax, Nova Scotia, to the conference participants at the $2^{\text {nd }}$ ECINEQ meeting in Berlin, and The International Conference on Experiences and Challenges in Measuring National Income and Wealth in Transition Economies, Beijing, and two perceptive referees. 


\begin{abstract}
China's One Child Policy (OCP) introduced in 1979 changed fundamentally the nature of both existing and anticipated marriage arrangements and influenced family formation decisions in many dimensions especially with respect to the number of and investment in children. The policy coincided with the Economic Reforms of 1979 and the trend towards greater urbanization, all of which may have influenced the well being of children. This paper examines the mobility status consequence of children in urban China since the introduction of the OCP and the economic reforms using data drawn from urban household surveys in China. The analysis first makes the comparison between child poverty in Canada, the United Kingdom and urban India, where it was found that both status and trends of child poverty are very different among the countries, with children not being over represented in the poverty group in urban China. The extent to which the policies influenced investment in children is next examined by studying the way in which the relationship between the educational attainment of children and family characteristics changed within families formed prior to and after 1979. We found that the impact of household income and parental educational attainment increased significantly over time, with a positive gender effect where girls advanced more than boys. Applying new techniques for measuring mobility, we observe the reduction in intergenerational mobility. This phenomenon is found to be particularly prevalent in the lower income quantiles reinforcing a dynastic notion of poverty.
\end{abstract}




\section{Introduction}

One of the most controversial and far reaching population control policies in recent history is China's One Child Policy (OCP) implemented in 1979 and followed since with some minor modifications. Directed at China's large population growth rate, the OCP represented a considerable intervention in the household choice process, where by fines and various other forms of coercion families were encouraged to limit the production of offspring. Over the same period child poverty has been a major issue in western (predominantly urban) societies where it is strongly associated with single parent family situations (in the United Kingdom children of lone parents are subject to more than twice the risk of poverty compared to children of couples (Brewer et. al. (2006a))). Its association with a lack of generational mobility and low investment in child quality has meant that its eradication has been an overt policy target in both Canada and the United Kingdom ${ }^{1}$, where child poverty figures of the order of 1 in 6 and 1 in 4 respectively have been cited in recent years (as compared to 1 in 10 and 1 in 7 respectively for people in poverty in the population at large). Though child poverty has not been such a direct policy target in the United States (where roughly speaking 1 in 5 children are in the poor group as compared with 1 in 10 households in the population at large) policies promoting generational mobility (reducing the dependence of child outcomes on parental circumstances) and investment in child quality (the "No Child Left Behind" for example) have been a policy imperative². In formalizing

\footnotetext{
${ }^{1}$ Without being very explicit, in 1989 the Canadian House of Commons unanimously resolved to "seek to achieve the goal of eliminating poverty among Canadian children by the year 2000" (to date a little progress has been made, though children are still over-represented in the poverty group). With a similar vagueness in 2000 , the British Government vowed to "half child poverty by 2010 and eliminate it by 2020 ", and to this end the U.K. government committed $£ 8$ billion to child contingent income support in the 1999-2004 period (Brewer et. al. (2006)) and some benefit has accrued, by 2004 the number of children in poverty had fallen by some 700,000 and the child poverty rate was at its lowest since the 1980's. These heroic intentions were not matched by the United States administration where the policy focus has been more on improving generational mobility (e.g. "Headstart" and "No Child Left Behind").

${ }^{2}$ All of this can be seen as an attack on the dynastic nature of poverty (Kanbur and Stiglitz (1989)) wherein children of the poor have a greater likelihood of being members of the poor "club" when they become adults.
} 
the mobility imperative, Roemer (2002) remarked that equal opportunity is "Probably the most universally supported conception of Justice advanced in societies..". With roots in recent egalitarian political philosophy (See Dworkin (1981)) the concept sees differential outcomes as ethically acceptable when they are the consequence of individual choice and action but not ethically acceptable when they are the consequence of circumstances beyond the individual's control.

The OCP intervention changed fundamentally the nature of both existing and anticipated marriage arrangements and influenced family formation decisions in many dimensions. Anderson and Leo (2007), in studying the impact of the policy on family formation construed the OCP as a rationing policy constraining the quantity (but not the quality) of children and, following Neary and Roberts (1980) and Deaton (1981), anticipated that the demand equations for quantity and quality of children would be affected accordingly. Increased positive assortative pairing of couples was observed as was increased investment in children and, also consistent with rationing theory, income ceased to be a factor in determining family size though it did become an increasingly important determining factor in investment in children. Such changes in family formation behavior may well have had substantial impacts on the short and long term wellbeing of children both in the context of child poverty, the level of investment in children and their generational mobility. Substantial economic growth (in part due to the economic reforms embarked upon at the same time as the OCP (Anderson and Ge (2004))) and rapid urbanization (Anderson and Ge (2005)) also took place at the same time making it difficult to attribute the child effects solely to the OCP (though theoretically it can be shown that growth would reduce the incidence of positive assortative pairing (Anderson and Leo (2007)). 
This raises issues, addressed in this research, as to whether or not similar circumstances prevail with respect to child poverty in urban China as in western societies where it is a matter of such concern, and whether or not the OCP and Economic Reforms had an influence on investment in children and generational mobility. The study is confined to urban China for two main reasons. The western societies with which comparison is being made are predominantly urban societies (the U.K. urban population is over $90 \%$, Canada's is over $85 \%$ ) and the child poverty issue is predominantly an urban feature in those societies. With respect to China (which is $39 \%$ urbanized according to the 2002 census and $28 \%$ urbanized according to Houkou registrations) the OCP appeared to be considerably more effective in the urban sector. The data are samples of family cohorts for the years 1987, 1989 and 1991 to 2001 drawn from an urban survey of six provinces in China, Shaanxi, Jilin, Hubei, Sichuan, Guangdong and Shandong ${ }^{3}$.

To anticipate some of the results, unlike the western experience, children do not appear to be over-represented in the poverty group either in terms of families formed before or after the OCP, indeed the sense in which they are under-represented seems to have strengthened over the period. However generational mobility does appear to have been substantially reduced over the period, a consequence perhaps of an increasing dependence upon the status of parents and of their investment in child quality, especially among the lower quantiles of the income distribution. Section 1 discusses the empirical strategy and the extent to which the observed changes can be attributed to the OCP and the economic reforms. In section 2 changes in the nature of child poverty are examined and compared with changes over a similar period in the U.K., Canada and urban India. Section 3 considers how increased investments in children in urban China have

\footnotetext{
${ }^{3}$ This dataset was obtained from the National Bureau of Statistics as part of the project on Income Inequality during China's Transition organized by Dwayne Benjamin, Loren Brandt, John Giles and Sangui Wang.
} 
impacted their educational attainment and Section 4 considers the changes in generational mobility in China over the period. Finally some conclusions are drawn in section 5.

\section{Empirical Strategy}

As noted in the introduction, the passing of the OCP in 1979 corresponded with the Economics Reforms of 1979. In so far as the economic growth policies has been successful, both of these policies could potentially lead to increased investments in children across all socioeconomic groups, thereby preventing the identification of the true indirect impact of the OCP on parental investment in children, and its consequent effect on intergenerational mobility, and incidence of child poverty. In this section, we will briefly discuss the dataset(s) used in our analysis, and the empirical strategy with which we hope to glean the impact of the OCP on children.

The Chinese dataset is drawn from the household survey from the National Bureau of Statistics of China for the years 1987, 1989, and 1991 to 2001. In the following section, we will examine the nature of child poverty in comparison with that of U.K., Canada, and urban India to illustrate the difference in structure, particularly the falling child poverty incidence among the urban populace in China. Based on the experience of developing economies such as exemplified by urban India, economic growth and urbanization is typically associated with increased incidences of child poverty as the poverty-gap increases. To the extent that the nature and incidence of child poverty differ between India and China, it may be indicative of the effect that OCP may have had on the urban populace of China. On the other hand, developed economies such as exemplified by the U.K. and Canada with the preponderance of social policies that aim at alleviating child poverty serve as a counterpoint to the effect of the OCP of China. To permit this comparison, we 
draw our U.K data from the annual Family Resources Survey, for Canada the Statistics Canada Survey of Household spending and for India the National Sample Survey rounds 50 and 60 from the Ministry of Statistics for urban India households.

In making the comparison between the four countries, we utilized Stochastic Dominance techniques to compare child and adult income size distributions. For this analysis, we used available comparable sample years from each country, specifically 1987 and 2001 for China, 1996 and 2002 for United Kingdom, 1997 and 2004 for Canada and 1994 and 2004 for India. Although all the Chinese sample years are after the OCP, we can think of the earliest 1987 sample as composed largely of families formed prior to the introduction of the OCP (particularly when we consider child and parent income realizations which constrains the sample to families with adult children) while the 2001 sample (as is clearly the case in each of the successive samples) as composed largely of families formed after the OCP. It is thus appropriate to address how we can elicit the effects of the OCP from such a collection of samples.

To understand this mixture of households formed before and after the OCP, first note that as mentioned above we may expect that the proportion of pre-OCP deciding households to diminish substantially over time in successive samples. Let the true pre-OCP and post-OCP density function of income or academic achievement characteristics, $x \in[0, \bar{x}]$, be $f_{\text {pre }}(x)$ and $g_{\text {post }}(x)$ respectively. Next, let the density function of the same characteristics for the 1987 sample be $f(x)$ such that it is a mixture of the pre-OCP decider households density $\left(f_{\text {pre }}(x)\right)$ and the post-OCP decider households density $\left(g_{\text {post }}(x)\right)$ in the form $\alpha_{f} f_{\text {pre }}(x)+\left(1-\alpha_{f}\right) g_{\text {post }}(x)$ where $\alpha_{f}$ is the proportion of pre-OCP deciding households in the $f($.$) distribution of 1987. In a similar fashion$ 
let the 2001 sample distribution $g(x)$ be a mixture of the form $\alpha_{g} f_{\text {pre }}(x)+\left(1-\alpha_{g}\right) g_{\text {post }}(x)$ where $\alpha_{g}$ is the proportion of pre-OCP deciding households in the $g($.$) distribution. Furthermore, it is$ reasonable to expect $\alpha_{f}-\alpha_{g}>0$, that is to say $f(x)$ is largely a household income distribution of pre-OCP deciders albeit in 1987 and $g(x)$ is largely a household income distribution of post-OCP deciders in 2001. It is then clear that even if the interest is in the underlying dominance relationship between $f_{\text {pre }}(x)$ and $g_{\text {post }}(x)$, the dominance relationship can still be examined by considering the mixture of two density functions. To see this note that in considering a dominance relationship between $f(x)$ corresponding to the adult distribution in 1987 and $g(x)$ corresponding to the child's distribution, we have for a $k^{\prime}$ th order dominance relationship:

$$
\begin{aligned}
\int \ldots \iint(f(x)-g(x)) d x d y \ldots d z & =\int \ldots \iint\left(\begin{array}{l}
\left(\alpha_{f} f_{\text {pre }}(x)+\left(1-\alpha_{f}\right) g_{\text {post }}(x)\right) \\
-\left(\alpha_{g} f_{\text {pre }}(x)+\left(1-\alpha_{g}\right) g_{\text {post }}(x)\right)
\end{array}\right) d x d y \ldots d z \\
& =\left(\alpha_{f}-\alpha_{g}\right) \int \ldots \iint\left(f_{\text {pre }}(x)-g_{\text {post }}(x)\right) d x d y \ldots d z
\end{aligned}
$$

If household decisions are thought to be made prior to age 25 based on the age of head of household, $\alpha_{f}$ is approximately 0.8079 and $\alpha_{g}$ is approximately 0.2768 in our samples so that the 1987 comparison will be that of predominantly pre-OCP deciders and the 2001 comparison will be that of predominantly post-OCP deciders. In so much as the OCP is peculiar to China, the change in the difference in the dominance relationship as compared to the three other countries allows us to glean for suggestive evidence that the OCP might have induced it.

To directly examine the changes in investments in children and the evolution of generational mobility we pooled all the cross-sectional data from 1987, 1989 and 1991 to 2001, and using the birth year of the mothers, separated the dataset into pre- and post-OCP families. A family is classified as possibly affected by the OCP (Post-OCP Family) if the mother was younger than 25 years of age at the onset of the OCP, and could have had at most one child by 1979. All other 
families are classified as "Pre-OCP Families", and further to minimize the selection problem due to truncation of observations within these families which are more likely to experience older children leaving the household to form their own families, we excluded families whose heads were born before the 1940's. The first criterion in creating the "Post-OCP Families" was selected based on the observed age of first birth among the populace, which is summarized in section 3 . The addition of the second criterion is because it is possible that a young women might have married early, and consequently have had more than one child by the onset of the OCP, that is her family size choice would not have been subject to the OCP. From this set of families, we then considered children over 19 and less than 30 inclusive, who can be attached to parents within the household, since in so doing we can ensure that parental investments in these children (as realized in their educational attainment) would have been more or less completed. Put another way, we ignore identifiable relationships between the head of household and their spouse with other relatives such as parent-in-laws. This is done since it is not possible to link all children of older members of the household (parent-in-laws) to their children, most of whom may not be in the same household. We will nonetheless examine the selection problems and their consequent biases in section 4 . Note that although all of the cross sectional data contributed to the pre-OCP observations, post-OCP observations occur only after 1998.

\section{Child Poverty and Wellbeing}

In western societies, concern with child poverty pertains to the over-representation of children in the poverty "club", alternatively put the children in those societies experience a greater degree of measured poverty than do the adults. How this poverty "club" is measured has been the subject of much debate. What should the poverty frontier be? Should incidence, depth or intensity 
measures be used? How should adults and children be compared within the context of a household? To what extent are there returns to scale in household consumption? All are issues that have received much attention. To this list should be added the question of the household sharing rule which permits the identification of child and adult income distributions? Thanks to Atkinson (1987) many of these debates (aside from the last few) may be circumvented by employing stochastic dominance techniques.

Atkinson's result, also noted in Foster and Shorrocks (1988), establishes a useful link between poverty indices and stochastic dominance relations for more general welfare comparisons which may be summarized as follows. If income distribution $F_{A}(x)$ stochastically dominates income distribution $F_{C}(x)$ over the interval 0 to $x^{*}, x^{*} \leq \bar{x}$, at a particular order, then all poverty measures in a specific class will record greater poverty for society $C$ than society $A$ for any poverty line up to $x^{*}$. Intensity of poverty measures require dominance of order three or less, depth of poverty measures require dominance of two or less and incidence measures (e.g. poverty rates) require dominance of order 1 . Noting that dominance of order $j$ implies dominance of order $k$ for $k>j$, we see that first order dominance of $A$ over $C$ implies greater poverty in $C$ than in $A$ for any poverty measure based upon a cut-off less than $x^{*}$. Thus in the present context, child $F_{C}(x)$ and adult $F_{A}(x)$ income distributions can be compared and if the former is stochastically dominated by the latter at all incomes less than $x^{*}$ we can conclude that children are over-represented in the poverty group regardless of the poverty index used as long as the poverty cutoff is less than $x^{*}$. 
Child and adult income distribution comparisons, computed on the basis of attributing the household equivalized income (using the square root rule) to each child or adult in the household ${ }^{4}$, are made for the China datasets for the years 1987 and 2001. Similar comparisons were calculated for the U.K. for 1996 and 2002, Canada for 1997 and 2004 and India for 1994 and $2004^{5}$. Summary statistics for the comparison distributions are reported in Table 1 . Note that the location measures for the child distributions are greater than the location measures for adult distributions in China whereas the situation is reversed in the U.K., Canada and India (note that all comparisons are in within country real terms). Child distributions are always less dispersed than the corresponding adult distributions in all comparisons. With the exception of the 1987 adult distribution in China, which possesses a much larger standard deviation compared to its child counterpart, relative variability is pretty stable across distributions.

Table 1: Sample characteristics log adult real equivalized household income

\begin{tabular}{l|rcccc}
\hline \hline & Mean & Median & $\begin{array}{c}\text { Standard } \\
\text { Deviation }\end{array}$ & $\begin{array}{c}\text { Coefficient } \\
\text { of Variation }\end{array}$ & $\begin{array}{c}\text { Sample } \\
\text { Size }\end{array}$ \\
\hline China Child 1987 & 4.7819 & 4.8548 & 0.6164 & 0.1289 & 3387 \\
China Adult 1987 & 4.5317 & 4.8040 & 1.2556 & 0.2771 & 2074 \\
\hline China Child 2001 & 8.8374 & 8.9197 & 0.8642 & 0.0978 & 10569 \\
China Adult 2001 & 8.6875 & 8.7916 & 0.9050 & 0.1042 & 3936 \\
\hline UK Child 1996 & 5.3423 & 5.3390 & 0.6380 & 0.1194 & 17386 \\
UK Adult 1996 & 5.5021 & 5.5277 & 0.6797 & 0.1235 & 60323 \\
\hline UK Child 2002 & 5.5985 & 5.6089 & 0.6750 & 0.1206 & 9401 \\
UK Adult 2002 & 5.7257 & 5.7703 & 0.7509 & 0.1311 & 32691 \\
\hline Canada Child 1997 & 10.0136 & 10.0858 & 0.6685 & 0.0668 & 13040 \\
Canada Adult 1997 & 10.1234 & 10.1721 & 0.6952 & 0.0687 & 34594 \\
\hline Canada Child 2004 & 10.3216 & 10.3658 & 0.6746 & 0.0654 & 9214 \\
Canada Adult 2004 & 10.3731 & 10.4193 & 0.7115 & 0.0686 & 26027 \\
\hline India Child 1994 & 11.3268 & 11.2815 & 0.5446 & 0.0481 & 67033 \\
India Adult 1994 & 11.4490 & 11.4012 & 0.5748 & 0.0502 & 141215 \\
\hline India Child 2004 & 11.9622 & 11.9234 & 0.4811 & 0.0402 & 12342 \\
India Adult 2004 & 12.0444 & 11.9996 & 0.5151 & 0.0429 & 13716 \\
\hline \hline
\end{tabular}

\footnotetext{
${ }^{4}$ Comparing child and adult income distributions in this way involves very strong implicit assumptions about the way income is allocated or shared within the family which is fundamentally an unobservable phenomenon. Different sharing rules would produce substantially different outcomes establishing what those rules may be is a matter for ongoing research (see Browning et. al. (2006) for instance). The sensitivity to the "square root rule" choice was checked for the Chinese results. They appear robust for all scaling values between 0.0 and 0.68 , thereafter no significant differences between child and adult distributions could be detected

${ }^{5}$ The non-China data used in this study relate to United Kingdom household income net of direct taxes drawn from the annual Family Resources Survey, for Canada the Statistics Canada Survey of Household spending and for India National Sample Survey (NSS) rounds 50 and 60 from the Ministry of Statistics for Urban India households.
} 
Diagram 1 illustrates the comparisons of the distributions. It is readily seen that for 2001 at every decile cut-off up to the $9^{\text {th }}$ there were smaller proportions of children in the group than there were adults, very much a property of the child's income distribution first order dominating that of the adults. Thus we can safely conclude that for almost any poverty measure at any cutoff line child poverty would be less than adult poverty. The same is almost true for the 1987 year where the proportion of children is always less than the proportion of adults for every decile cut-off up to the $7^{\text {th }}$, so that child poverty would be less than adult poverty for any poverty line up to the $7^{\text {th }}$ decile for virtually all poverty measures. Actually $1^{\text {st }}$ order dominance would be rejected over the whole income range since for the $8^{\text {th }}$ and $9^{\text {th }}$ deciles child shares are significantly greater than adult shares but second order dominance of the adult income distribution by the child's distribution would prevail (see appendix 1 for details) so that all depth and intensity poverty measures would record less poverty for children than for adults over the whole income range.

Diagrams 1a, 1b and 1c illustrate the corresponding comparisons for the selected years for Canada, the U.K. and India respectively. Notice that for the U.K. and India comparators the reverse is true, at every decile cut-off up to the $9^{\text {th }}$ the child's income share is greater than the adult's (both in 1996 and 2002), very much a characteristic of the adult income distribution stochastically dominating the child's income distribution at all orders indicating an overrepresentation of children in the poverty group however defined. The same is true for Canada except for the $2^{\text {nd }}$ decile in the 2004 comparison (but this difference is not significantly different from 0 and not enough to contradict the same dominance result as for the U.K. and India). 


\section{Diagram 1}

Child and Adult Shares at Population Income Deciles China 2001

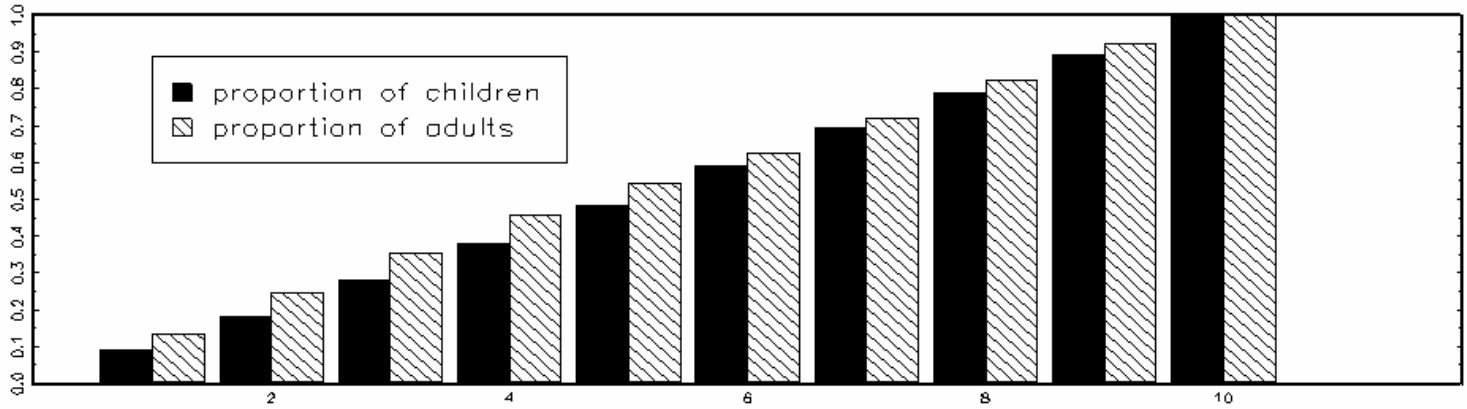

Child and Adult Shares at Population Income Deciles China 1987

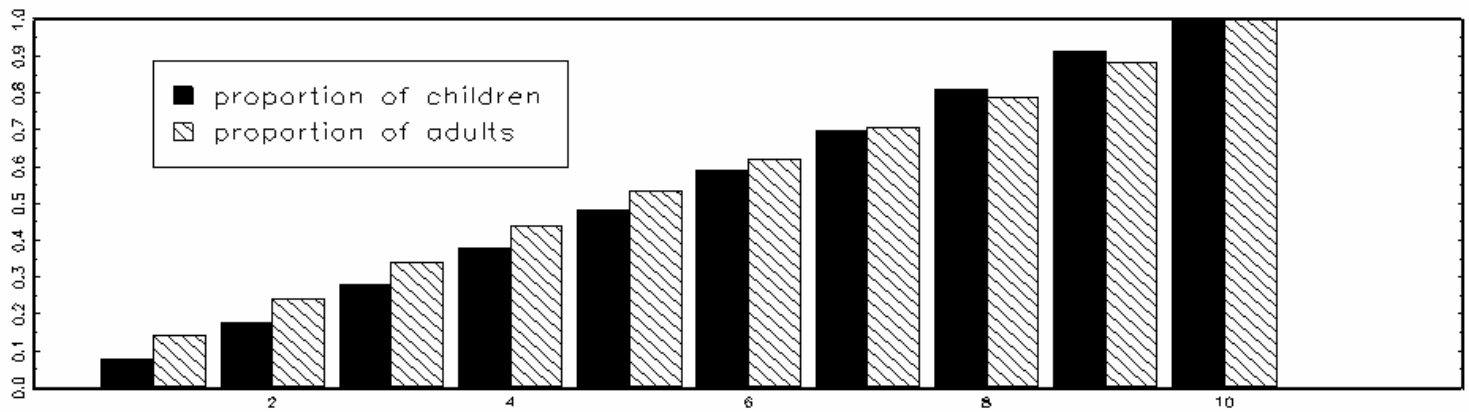

Diagram 1a

Child and Adult Shares at Population Income Deciles Canada 2004

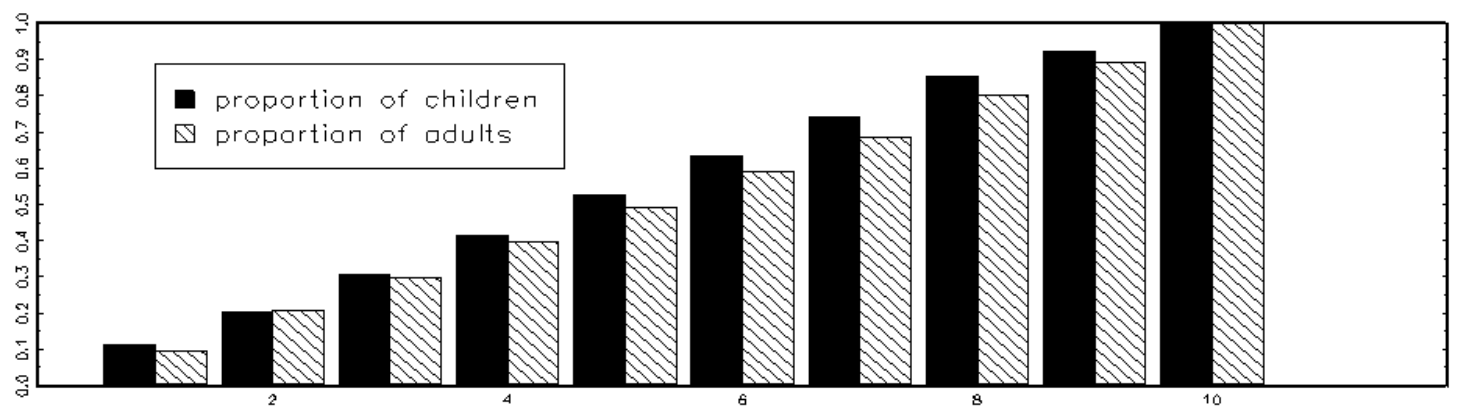

Child and Adult Shares at Population Income Deciles Canada 1997

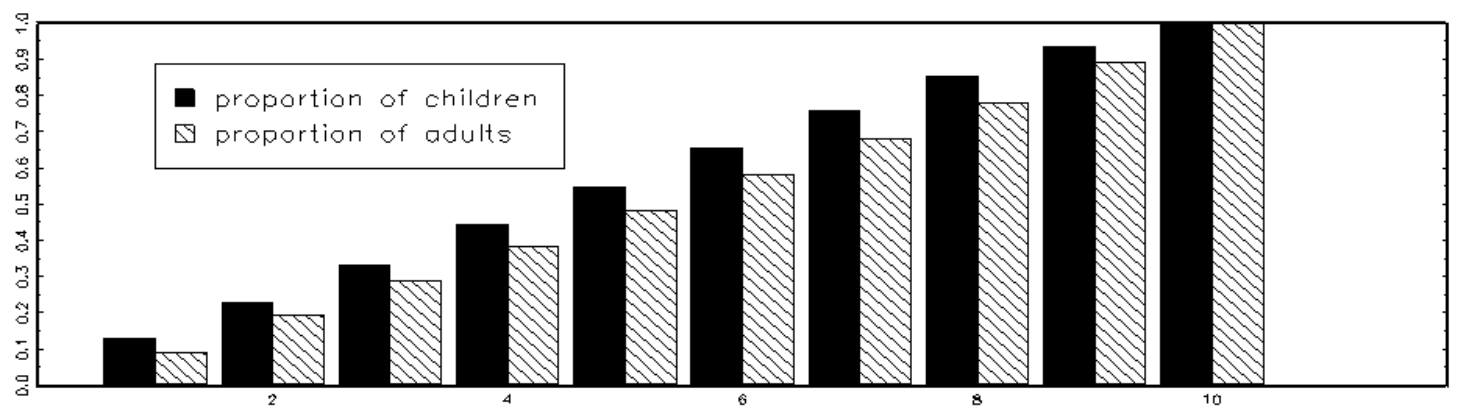


Diagram 1b

Child and Adult Shares at Population Income Deciles UK 2002

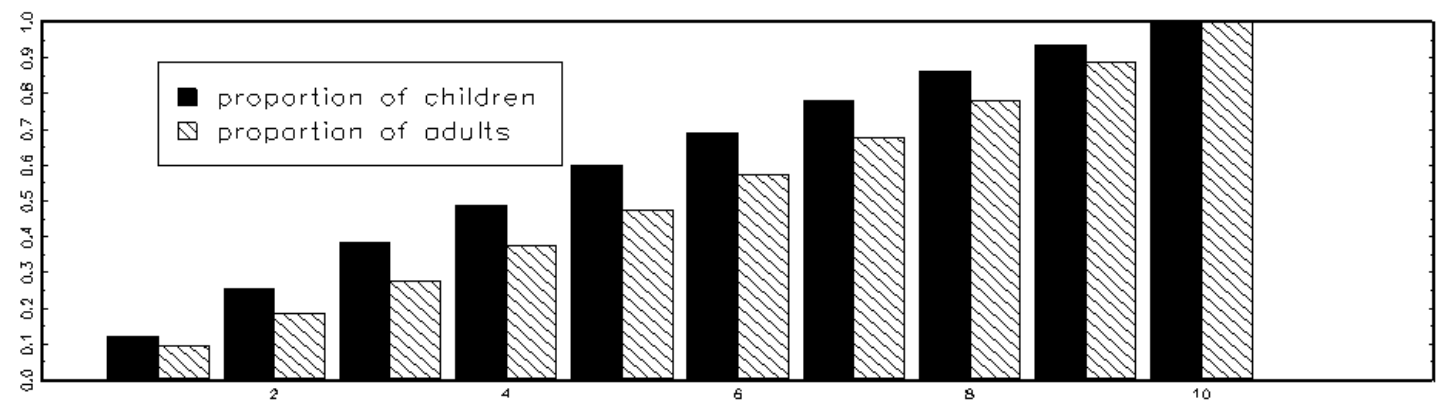

Child and Adult Shares at Population Income Deciles UK 1996

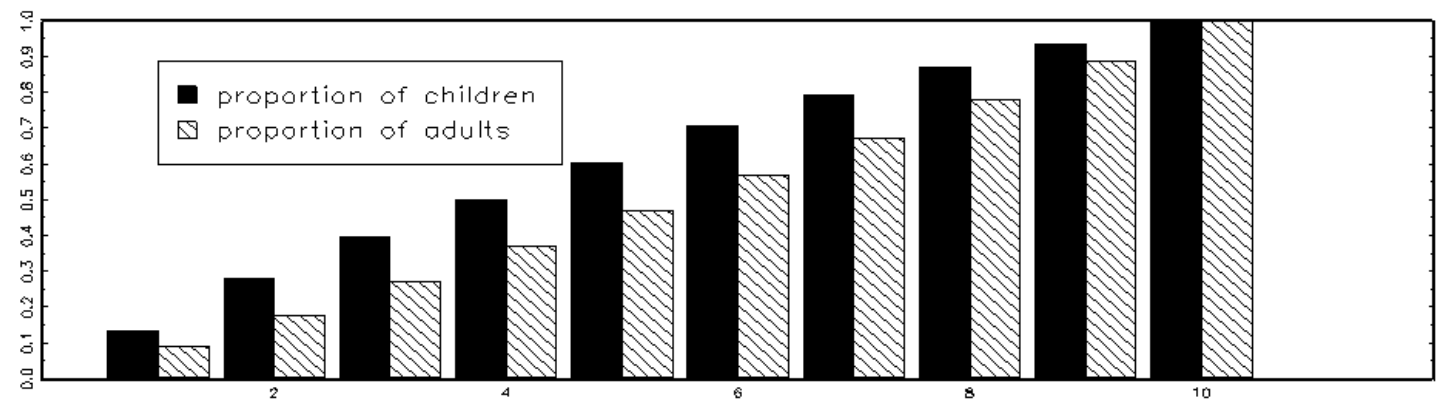

Diagram 1c

Child and Adult Shares at Population Income Deciles India 1994

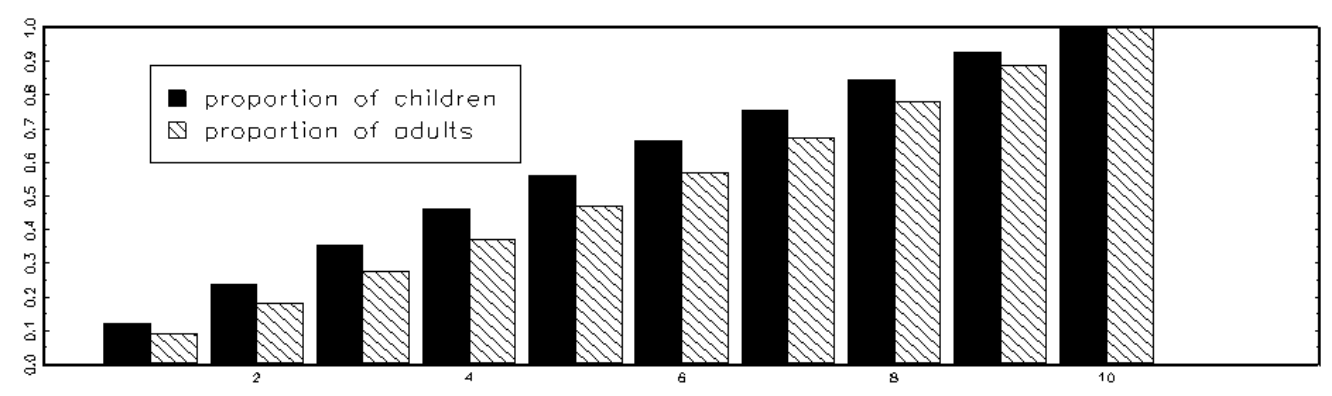

Child and Adult Shares at Population Income Deciles India 2004

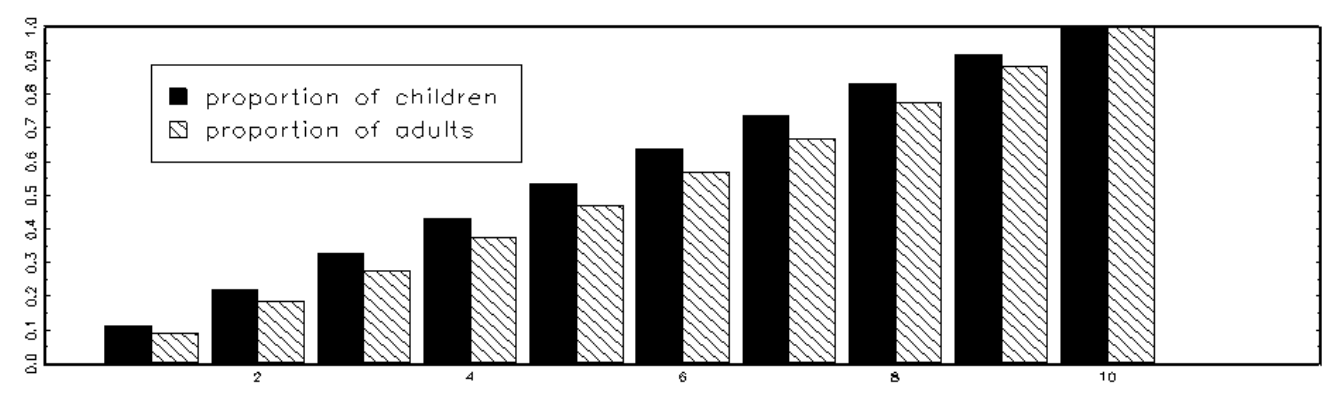


In essence the comparisons which permitted such strong and sweeping statements to be made were of the form:

$$
\int_{0}^{x}\left(F_{C}^{i}(z)-F_{A}^{i}(z)\right) d z \leq 0 \forall x
$$

where $F_{H}^{i^{\prime}}(x)=\int_{0}^{x} F_{H}^{i}(z) d z, i^{\prime}=i+1$ and $F_{H}^{0}(z)=f_{H}(z)$ for $H=A, C$ and $i=\{1,2, \ldots\}$. These are conditions under which we can infer that society $C$ is better off than society $A$. Thus from the above, for China it may be inferred that the society of children were better of than the society of adults for all utilitarian social welfare functions in 2001 and for all social welfare functions that express a preference for mean preserving progressive transfers in 1987 . The reverse is true for the U.K., Canada and India in both their respective comparison periods and the society of adults is better off than the society of children in terms of all utilitarian social welfare functions. However we can take the analysis further, consider the income distribution of society $H$ in year $k$ to be $F_{H, k}(x)$ and consider the condition:

$$
\int_{0}^{x}\left(\left(F_{C, 2001}^{i}-F_{A, 2001}^{i}\right)-\left(F_{C, 1987}^{i}-F_{A, 1987}^{i}\right)\right) d z \leq 0, \forall x, i \in\{1,2, \ldots\}
$$

This responds to the question: "Does the extent to which the child's society was better off than the adult's in 2001 dominate the extent to which the child's society was better off than the adult's in1987?". This is essentially a difference in dominance comparison, part of the toolkit for studying polarization (Anderson (2004)). The comparison results employing the Wolak (1989) method for comparing multivariate inequalities are reported in Table 2 for China 2001 and 1987, for Canada 2004 and 1997, for the UK 2002 and 1996 and for India 2004 and 1994. 
Table 2: Difference in differences comparisons, upper tail probabilities

\begin{tabular}{lcc}
\hline \hline Comparison & $\begin{array}{c}\text { Adult Change Dominates } \\
\text { Child Change }\end{array}$ & $\begin{array}{c}\text { Child Change Dominates } \\
\text { Adult Change }\end{array}$ \\
\hline China 1987-2001 & 0.0000 & 0.9409 \\
Canada 1997-2004 & 0.0000 & 0.8925 \\
United Kingdom 1996-2002 & 0.0000 & 0.9007 \\
India 1994-2004 & 0.0000 & 0.9305 \\
\hline \hline
\end{tabular}

In the case of all of the countries, the notion that the change in the child's distribution dominated that of the adult's distribution is not rejected, whereas the notion that the change in the adult's distribution dominated that of the children is strongly rejected. Because the initial conditions differ, this has different implications for China as compared to the other countries. For China it means that the child's income distribution has moved further away from the adult's income distribution, child and adult societies have become more polarized as it were, whereas for Canada, India and the United Kingdom it means that child and adult groups in those societies have moved closer together or depolarized, in other words children are catching up here in a welfare sense. It is thus safe to conclude that, on the basis of our samples, relative to adult poverty, child poverty is not the issue in China that it appears to be in the other societies under comparison, indeed one may ask why there is no concern over increasing relative adult poverty! To the extent that the 1987 China sample consists completely of families that must have been formed prior to the OCP, while the 2001 sample is interspersed with families that have lived through the OCP and the economic gains due to the Economic Reforms of 1979 suggests that either one if not both of the policy might have been causal. When viewed in the context of the dedicated poverty elimination policies of the U.K. and Canada, and the economic growth of India over the sample period seems to suggest that the domineering effect might be the rationing effect of the OCP on China. The following section investigates the changes in educational attainment between prior cohorts of children versus the cohort that lived through the OCP. 


\section{Investment in Children}

One feature of the OCP impact on family formation noted in Anderson and Leo (2007) is the increased investment in child quality. To illustrate the issue here, investment in children as reflected in their educational attainments is examined. As noted in section 1, for comparison purposes only children between the ages of 19 and 30 are studied so that the parental aspect of the investment activity may assume to have been completed and cohorts of such children were derived from all samples from 1987, 1989 and 1991 to 2001, and for all six provinces, separating the samples into pre-OCP families consisting of mothers who were 25 years old and older in 1979 (including also younger mothers who had more than 1 child by 1979 since the OCP would not have been binding on them), and post-OCP families with mothers who were younger than 25 in 1979 (with at most one child by 1979).

The summary of some of the variables are reported in table 3. Note that both groups have very similar age at first birth among the mothers in both pre- and post-OCP cohorts, and the substantially lower number of children per family after the OCP. In addition, despite the fact that pre-OCP parents being more advanced in their careers, the average deflated and equivalized ${ }^{6}$ incomes of pre-OCP parents are all lower than their post-OCP counterparts, this in spite the fact that post-OCP fathers had marginally lower educational attainment, while post-OCP mothers had higher educational attainment compared to the pre-OCP cohort. This is likely due to the increased positive assortative matching and lower marriage rates noted in Anderson and Leo (2007).

${ }^{6}$ Deflated as suggested by Brandt and Holz (2006). 
Table 3: Summary of Individual and Household Characteristics

\begin{tabular}{|c|c|c|}
\hline Variables & Pre-OCP & Post-OCP \\
\hline \multirow[t]{2}{*}{ Mother's Age at First Birth } & 25.77 & 24.38 \\
\hline & $(3.17)$ & (1.7) \\
\hline \multirow[t]{2}{*}{ Father's Age at First Birth } & 29.08 & 27.07 \\
\hline & $(3.89)$ & $(2.54)$ \\
\hline \multirow[t]{2}{*}{ Age } & 21.97 & 19.61 \\
\hline & $(2.48)$ & $(0.79)$ \\
\hline Proportion Female & 0.46 & 0.51 \\
\hline \multirow[t]{2}{*}{ Educational Attainment } & 3.45 & 3.54 \\
\hline & (1.07) & $(1.02)$ \\
\hline \multirow[t]{2}{*}{ Birth Order } & 1.42 & 1.14 \\
\hline & $(0.62)$ & $(0.38)$ \\
\hline \multirow[t]{2}{*}{ Family Size } & 3.91 & 3.35 \\
\hline & $(0.81)$ & $(0.6)$ \\
\hline \multirow{2}{*}{$\begin{array}{l}\text { Deflated \& Equivalized Father's } \\
\text { Income ('000s) }\end{array}$} & 2.22 & 2.79 \\
\hline & $(2.04)$ & $(2.98)$ \\
\hline \multirow{2}{*}{$\begin{array}{l}\text { Deflated \& Equivalized Mother's } \\
\text { Income ('000s) }\end{array}$} & 1.56 & 1.93 \\
\hline & $(1.55)$ & $(2.17)$ \\
\hline \multirow[t]{2}{*}{ Father's Education } & 3.04 & 2.95 \\
\hline & (1.37) & $(1.24)$ \\
\hline \multirow[t]{2}{*}{ Mother's Education } & 2.44 & 2.6 \\
\hline & $(1.24)$ & (1) \\
\hline \multirow[t]{2}{*}{ Father's Age } & 51.75 & 46.73 \\
\hline & (4.6) & (2.62) \\
\hline \multirow[t]{2}{*}{ Mother's Age } & 48.44 & 44.04 \\
\hline & $(3.78)$ & $(1.67)$ \\
\hline \multirow[t]{2}{*}{ Number of Children } & 1.83 & 1.26 \\
\hline & $(0.75)$ & $(0.51)$ \\
\hline Number of Observations & 11154 & 492 \\
\hline \multicolumn{3}{|l|}{ Note: } \\
\hline $\begin{array}{l}\text { 1. Standard Deviations in parent } \\
\text { 2. Educational attainment is } 1 \\
\text { and above, } 4=\text { technical } \\
\text { school and lower }\end{array}$ & $\begin{array}{l}\text { ian in bracl } \\
\text { an integer } \\
\text { hool, } 3=\end{array}$ & $\begin{array}{l}5=\text { college graduates } \\
\text { school, } 1=\text { primary }\end{array}$ \\
\hline
\end{tabular}

Table 4 reports the results of the stochastic dominance comparisons of educational attainment between the pre- and post-OCP cohorts of children. The first two rows under each attainment reports the cumulative distribution (First Order Stochastic Dominance) up to the educational 
measure, while the third and fourth rows reports the second order stochastic dominance statistics. It is clear that the post-OCP cohort first order stochasticially dominates the pre-OCP cohort at all levels of educational attainment suggesting there were indeed significant gains in child attainment.

Table 4: Stochastic Dominance Test between Pre- and Post OCP Cohorts

\begin{tabular}{l|ccc}
\hline \hline Educational & Pre-OCP & Post-OCP & Difference \\
Attainment & 0.0120 & 0.0000 & 0.0120 \\
\hline Primary or Less & $(0.0010)$ & $(0.0000)$ & {$[1.0000]$} \\
& 0.0120 & 0.0000 & 0.0120 \\
Middle School & $(0.0010)$ & $(0.0000)$ & {$[1.0000]$} \\
& 0.1807 & 0.1301 & 0.0507 \\
High School & $(0.0036)$ & $(0.0152)$ & {$[0.9994]$} \\
& 0.9037 & 0.6504 & 0.2533 \\
& $(0.0076)$ & $(0.0303)$ & {$[1.0000]$} \\
& 0.5993 & 0.5854 & 0.0139 \\
Technical School & $(0.0046)$ & $(0.0222)$ & {$[0.7297]$} \\
& 8.3895 & 8.1951 & 0.1943 \\
& $(0.0182)$ & $(0.0817)$ & {$[0.9899]$} \\
& 0.7554 & 0.7398 & 0.0156 \\
& $(0.0041)$ & $(0.0198)$ & {$[0.7799]$} \\
& 22.6630 & 22.1950 & 0.4676 \\
& $(0.0313)$ & $(0.1465)$ & {$[0.9991]$} \\
\hline \hline
\end{tabular}

Note: 1. Standard errors are in parenthesis, and p-values are in brackets. 2. The first two rows for each educational attainment level are for first order stochastic dominance comparisons while the third and fourth rows are for second order stochastic dominance comparisons.

To examine the determinants of child quality, educational attainment is regressed upon the logarithm of total parental equivalized income, father's and mother's educational status, household size (including all members of the extended family), and the gender of the child ( 1 if female, 0 otherwise) and birth order (representing the order in which the child arrived in the family, 1 = first child, 2 = second child...). Family consumption deflated (Brandt and Holz 
(2006)) income equivalization is based upon the square root rule (Brady and Barber (1948)) under which family income is divided by the square root of the number of persons in the family (as opposed to the household) and reflects returns to scale in family consumption. Parental educational status is included to reflect both inherited abilities and parental preferences, household size is included independently of family income to reflect investment scale effects beyond the consumption nexus. Gender and birth order effects are included following Bjorklund et. al (2004) and Kantarevic and Mechoulan (2006).

Table 5 reports regressions for the pre-OCP and post-OCP cohorts which were performed for single child, and two child family situations ${ }^{7}$. Examining single child families in both panel A and $\mathrm{B}$, note the great similarity for both the pre- and post-OCP families in the effect parental income and father's educational attainment has on child educational attainment. Despite the differences due to household size, and the effect of the child being female (both of which are not statistically significant), there is in fact no difference in the "production technology" between the two cohorts. This however is not surprising since the choice of investment is predicated on the same number of children, consequently whether that choice is exogenously imposed or independently chosen, there should be no difference in the effect on investment.

\footnotetext{
${ }^{7}$ Although there were sufficient observations to examine the production technology of families with more than 2 children in the pre-OCP state, this family structure is rare in the post-OCP state, and consequently has been left out of our analysis.
} 
Table 5: Child Educational Attainment Regressions

\begin{tabular}{|c|c|c|}
\hline Panel A: Pre-OCP & 1 Child Families & 2 Child Families \\
\hline Deflated \& Equivalized Family Income & $\begin{array}{c}0.3472 \\
(0.0351)\end{array}$ & $\begin{array}{c}0.2964 \\
(0.0282)\end{array}$ \\
\hline Father's Education & $\begin{array}{c}0.1254 \\
(0.0128)\end{array}$ & $\begin{array}{c}0.1193 \\
(0.0105)\end{array}$ \\
\hline Mother's Education & $\begin{array}{c}0.1252 \\
(0.0140)\end{array}$ & $\begin{array}{c}0.1681 \\
(0.0120)\end{array}$ \\
\hline Household Size & $\begin{array}{c}0.0225 \\
(0.0524)\end{array}$ & $\begin{array}{c}0.0633 \\
(0.0468)\end{array}$ \\
\hline Female & $\begin{array}{c}0.1004 \\
(0.0308)\end{array}$ & $\begin{array}{c}0.0890 \\
(0.0260)\end{array}$ \\
\hline Birth Order & & $\begin{array}{c}0.0452 \\
(0.0259)\end{array}$ \\
\hline Parental Cohort Dummies & Yes & Yes \\
\hline Provincial \& Year Dummies & Yes & Yes \\
\hline $\mathbf{R}^{2}$ & 0.2122 & 0.2085 \\
\hline $\boldsymbol{\sigma}$ & 0.9516 & 0.9488 \\
\hline Number of Observations & 3978 & 5390 \\
\hline Panel B: Post-OCP & 1 Child Families & 2 Child Families \\
\hline Deflated \& Equivalized Family Income & $\begin{array}{c}0.3022 \\
(0.0850)\end{array}$ & $\begin{array}{c}0.5827 \\
(0.1966)\end{array}$ \\
\hline Father's Education & $\begin{array}{c}0.1293 \\
(0.0467)\end{array}$ & $\begin{array}{c}0.3157 \\
(0.0711)\end{array}$ \\
\hline Mother's Education & $\begin{array}{c}0.0514 \\
(0.0580)\end{array}$ & $\begin{array}{c}0.1119 \\
(0.0883)\end{array}$ \\
\hline Household Size & $\begin{array}{l}-0.1636 \\
(0.1231)\end{array}$ & $\begin{array}{l}-0.9707 \\
(0.6185)\end{array}$ \\
\hline Female & $\begin{array}{c}0.0853 \\
(0.0987)\end{array}$ & $\begin{array}{c}0.3971 \\
(0.1715)\end{array}$ \\
\hline Birth Order & & $\begin{array}{l}-0.2387 \\
(0.1680)\end{array}$ \\
\hline Parental Cohort Dummies & Yes & Yes \\
\hline Provincial \& Year Dummies & Yes & Yes \\
\hline $\mathbf{R}^{2}$ & 0.2138 & 0.4333 \\
\hline$\sigma$ & 0.9368 & 0.7701 \\
\hline Number of Observations & 376 & 103 \\
\hline Test of Difference, F Statistic [p-value] & $0.1562[1.0000]$ & $1.4415[0.1126]$ \\
\hline
\end{tabular}

Standard Errors are in parenthesis, and p-values are in brackets. 
On the other hand, comparing families with two children, note the significant increase in the income effect (doubling from approximately 29 percentage point to 58 percentage point) and the paternal effect on educational attainment in their children, while the maternal effect waned. In addition, note the significant increase in the female effect, suggesting greater investments were placed with female children among these families. Although birth order was positive among preOCP cohorts, this changed sign among post-OCP children. Despite these differences, test of the restriction that all the coefficients for both pre- and post-OCP cohorts are the same cannot be rejected.

A possible reason for the stronger connection in income and paternal educational attainment among families with more than one child is that the former is a prerequisite to circumvent the OCP, thereby creating the significant differential between the pre- and post-OCP cohorts. In so far as the primary determinant of family income is dependent on paternal labour supply, the increase in paternal educational effect is likewise then not surprising. However, given the concurrent effects of the Economic Reforms, the former argument may not be binding without the economic growth that was generated. With respect to the increase in female effect, it is possible that it is a reaction to marriage market sex ratio (see table 3 ) so as to enhance the probability of a good spousal match for their daughters and personal wealth through the labour market (Peters and Siow (2002)).

\section{Generational Mobility}

Greater parental investments in child quality undoubtedly strengthen the ties between generational income distributions, making it more likely that parents with high (low) incomes 
will have children who will earn high (low) incomes when they become adults. This increased dependence between child and parent outcomes constitutes a reduction generational mobility. Here the generational mobility phenomenon is examined by studying the dependence between parent incomes and educational attainments and child educational attainments.

Mobility has mostly been studied in the context of intergenerational income transitions (see Corak $(2004,2006)$ for a survey and examples) generally assessed via the regression coefficient $(\beta)$ of the child income $(y)$ on the corresponding parent income $(x)$ inferring mobility (equal opportunity) as $\beta \rightarrow 0$ and immobility (unequal opportunity) as $\beta \rightarrow 1$. However mobility interpretations of $\beta$ are limited by its connection to the correlation coefficient $\rho_{y x}\left(\beta=\rho_{y x}\left(\sigma_{y} / \sigma_{x}\right)\right)$, and its ability to reflect dependence. In addition, it is constrained by the implicit assumption that $y$ and $x$ are homogeneously linear across all socioeconomic strata ${ }^{8}$. However if the degree of dependence is the issue and the setting is not homogeneous, the transition matrix between the common quantiles of the marginal densities $f(x)$ and $g(y)$ can be more informative. This has given rise to the application of techniques derived from Markov Chain processes and the development of mobility indices, some based upon the nature of the transition matrix directly (with complete mobility the columns of a transition matrix are identical), some based upon other related concepts 9 . When the quantiles or categories of $f(x)$ and $f(y)$ match or are common, such an analysis is straightforward, but there are significant difficulties when they are not. Here, since the

\footnotetext{
${ }^{8}$ As an index $\beta$ would not prove very effective if immobility were just confined to the lowest income group for example. Indeed there are dangers with interpreting zero correlation with perfect mobility, imagine a deterministic world (perfectly immobile) where below a certain parental income there is an exact negative relationship between parent and child outcomes whereas above that income there is an exact positive relationship between parent and child outcomes, an appropriately balanced sample would yield 0 correlation with an inferred perfect mobility for what is a completely deterministic and immobile state.

${ }^{9}$ Bartholemew (1982), Blanden et. al. (2004), Chakravaty (1995), Dearden et. al. (1997), Hart (1983), Maasoumi (1986), Maasoumi and Zandvakili (1986), Prais (1955), Shorrocks (1976), (1978) have all produced "Transition" based mobility indices many of which are discussed in Maasoumi (1995)).
} 
data does not present in terms of the common quantiles of two single variables, we consider more general transition processes between generations characterized by different sets of characteristics which do not readily lend themselves to a Markov chain interpretation.

Following Anderson, Ge and Leo (2008) and Anderson and Leo (2006) the extent to which independence accords with the data can be indexed by an overlap measure given by:

$$
\mathrm{OV}=\sum_{i} \sum_{j} \min \left\{p_{i, j}^{o}, p_{i, j}^{e}\right\}
$$

where $p_{i, j}^{o}$ corresponds to the $i, j^{\text {th }}$ cell probability of the observed joint probability matrix and $p_{i, j}^{e}$ corresponds to the $i, j^{\text {th }}$ cell probability of the expected joint probability under the null hypothesis of independence where $i$ corresponds to the $i^{\text {th }}$ child characteristic configuration and $j$ corresponds to the $j^{\text {th }}$ parental characteristic configuration. This measure forms a very natural index since it reflects the proximity of the data to the hypothesis of interest, which is that child characteristic realization is independent of parental characteristic(s). When the data completely conform to the hypothesis of interest (in this case independence) $O V=1$, otherwise $0 \leq O V<1$.

$O V$ is easily calculated, $p_{i, j}^{o}$ is simply estimated from the observed cell sample proportions and $p_{i, j}^{e}$ is estimated from the product of the corresponding empirical marginal proportions. An attractive feature of this index is that they can be readily applied when the underlying parent child transition matrices are not square and transitions are between multivariate environments. For example given continuously measured parental characteristics $w$ and $x$ with joint density $f(w, x)$ and continuously measured child characteristics $y$ and $z$ with joint density $g(y, z)$ and a joint density of all characteristics given by $h(w, x, y, z)$, then $O V$ estimates the magnitude $\iiint \min [h(w, x, y, z),(f(w, x) g(y, z))] d w d x d y d z$. In addition they are asymptotically normal sampling distributions (See Anderson, Ge and Leo (2008)), conveniently facilitating inferences about 
trends toward or away from independence over time. Further, these indices can be more focused, concentrating on a subset of cells that relate to particular features of interest. So for example mobility amongst the poor could be examined by specifying a null in which only independence with respect to the poor is entertained so that the mobility of the $i^{\text {th }}$ subgroup can be considered in terms of:

$$
O V_{i}=\sum_{j \in\{1, K\}} \min \left\{\frac{p_{i, j}}{p_{i}}, p_{j}\right\}
$$

where $p_{i}$ and $p_{j}$ are marginal row and column probabilities respectively ${ }^{10}$.

To study the impact on generational mobility due to the OCP, we examine the changes in the degree of dependence between parent and child characteristics pre- and post-OCP. The samples used are as that in section 3, and parental characteristics considered are family income and parental educational attainment (the maximum of the parent's attainments), while the child's characteristics are their educational attainments. As before in section 3, only children between the ages of 19 and 30 residing with their parents were considered so as to allow for them to have completed their education. In addition to overall parent-child mobility, mobility by gender and birth order of child are considered following Bjorkland et.al. (2004). Both univariate (Parent Achievement-Child Achievement and Parent Income-Child Achievement), multivariate indices (Parent Achievement and Income-Child Achievement) are employed and are reported in table 6. Examining first panel $\mathrm{A}$, it is clear that in the education-education comparison, as well as the multivariate comparison reveals a diminished level of mobility, while the slight increase in mobility for the income-education comparison is not statistically significant, suggesting that the

\footnotetext{
${ }^{10}$ This possibility calls for a concept of "Qualified Equal Opportunity" or "Conditional Mobility" which has been developed elsewhere (Anderson, Leo and Muelhaupt (2008)).
} 
improvement is driven by parental educational attainment, which may be interpreted as nonpecuniary inheritance.

Table 6: Mobility Differences Pre- and Post- OCP families

\begin{tabular}{|c|c|c|c|}
\hline $\begin{array}{l}\text { Panel A: Mobility of All } \\
\text { Children }\end{array}$ & Pre-OCP Families & Post-OCP Families & Difference \\
\hline $\begin{array}{l}\text { Mobility-All Children, } \\
\text { Education-Education }\end{array}$ & $\begin{array}{c}0.8796 \\
(0.0031)\end{array}$ & $\begin{array}{c}0.8463 \\
(0.0163)\end{array}$ & $\begin{array}{c}0.0334 \\
{[0.0439]}\end{array}$ \\
\hline $\begin{array}{l}\text { Mobility-All } \\
\text { Income-Education }\end{array}$ & $\begin{array}{c}0.8706 \\
(0.0032)\end{array}$ & $\begin{array}{c}0.8899 \\
(0.0141)\end{array}$ & $\begin{array}{l}-0.0193 \\
{[0.1829]}\end{array}$ \\
\hline $\begin{array}{l}\text { Mobility-All Children, } \\
\text { Education-Income-Education }\end{array}$ & $\begin{array}{c}0.8069 \\
(0.0037)\end{array}$ & $\begin{array}{c}0.7460 \\
(0.0196)\end{array}$ & $\begin{array}{c}0.0607 \\
{[0.0023]}\end{array}$ \\
\hline No. of Observations & 11154 & 492 & \\
\hline $\begin{array}{l}\text { Panel B: Mobility of Male } \\
\text { Children }\end{array}$ & Pre-OCP Families & Post-OCP Families & Difference \\
\hline $\begin{array}{l}\text { Mobility-Male Children, } \\
\text { Education-Education }\end{array}$ & $\begin{array}{c}0.8882 \\
(0.0041)\end{array}$ & $\begin{array}{c}0.8547 \\
(0.0227)\end{array}$ & $\begin{array}{c}0.0335 \\
{[0.1459]}\end{array}$ \\
\hline $\begin{array}{l}\text { Mobility-Male Children, } \\
\text { Income-Education }\end{array}$ & $\begin{array}{c}0.8715 \\
(0.0043)\end{array}$ & $\begin{array}{c}0.8688 \\
(0.0217)\end{array}$ & $\begin{array}{c}0.0027 \\
{[0.9026]}\end{array}$ \\
\hline $\begin{array}{l}\text { Mobility-Male Children, } \\
\text { Education-Income-Education }\end{array}$ & $\begin{array}{c}0.8091 \\
(0.0051)\end{array}$ & $\begin{array}{c}0.7289 \\
(0.0286)\end{array}$ & $\begin{array}{c}0.0802 \\
{[0.0057]}\end{array}$ \\
\hline No. of Observations & 5997 & 242 & \\
\hline $\begin{array}{l}\text { Panel C: Mobility of Female } \\
\text { Children }\end{array}$ & Pre-OCP Families & Post-OCP Families & Difference \\
\hline $\begin{array}{l}\text { Mobility-Female Children, } \\
\text { Education-Education }\end{array}$ & $\begin{array}{c}0.8593 \\
(0.0048)\end{array}$ & $\begin{array}{c}0.7986 \\
(0.0254)\end{array}$ & $\begin{array}{c}0.0608 \\
{[0.0186]}\end{array}$ \\
\hline $\begin{array}{l}\text { Mobility-Female Children, } \\
\text { Income-Education }\end{array}$ & $\begin{array}{c}0.8631 \\
(0.0048)\end{array}$ & $\begin{array}{c}0.8787 \\
(0.0206)\end{array}$ & $\begin{array}{l}-0.0156 \\
{[0.4609]}\end{array}$ \\
\hline $\begin{array}{l}\text { Mobility-Female Children, } \\
\text { Education-Income-Education }\end{array}$ & $\begin{array}{c}0.7905 \\
(0.0057)\end{array}$ & $\begin{array}{c}0.6979 \\
(0.0290)\end{array}$ & $\begin{array}{c}0.0926 \\
{[0.0017]}\end{array}$ \\
\hline No. of Observations & 5157 & 250 & \\
\hline
\end{tabular}


Table 6 Cont'd: Mobility Differences Pre- and Post- OCP families

\begin{tabular}{|c|c|c|c|}
\hline Panel D: Mobility of $1^{\text {st }}$ Born & Pre-OCP Families & Post-OCP Families & Difference \\
\hline \multirow{2}{*}{$\begin{array}{l}\text { Mobility-1 }{ }^{\text {st }} \text { Born, } \\
\text { Education-Education }\end{array}$} & 0.8769 & 0.8574 & 0.0195 \\
\hline & $(0.0039)$ & $(0.0169)$ & {$[0.2620]$} \\
\hline \multirow{2}{*}{$\begin{array}{l}\text { Mobility-1 }{ }^{\text {st }} \text { Born, } \\
\text { Income-Education }\end{array}$} & 0.8669 & 0.8877 & -0.0208 \\
\hline & $(0.0040)$ & $(0.0153)$ & {$[0.1880]$} \\
\hline \multirow{2}{*}{$\begin{array}{l}\text { Mobility- } 1^{\text {st }} \text { Born, } \\
\text { Education-Income-Education }\end{array}$} & 0.7973 & 0.7469 & 0.0504 \\
\hline & $(0.0047)$ & $(0.0211)$ & {$[0.0196]$} \\
\hline No. of Observations & 7221 & 426 & \\
\hline Panel E: Mobility of $2^{\text {nd }}$ Born & Pre-OCP Families & Post-OCP Families & Difference \\
\hline \multirow{2}{*}{$\begin{array}{l}\text { Mobility-2 }^{\text {nd }} \text { Born, } \\
\text { Education-Education }\end{array}$} & 0.8768 & 0.7227 & 0.1541 \\
\hline & $(0.0057)$ & $(0.0569)$ & {$[0.0070]$} \\
\hline \multirow{2}{*}{$\begin{array}{l}\text { Mobility-2 }{ }^{\text {nd }} \text { Born, } \\
\text { Income-Education }\end{array}$} & 0.8866 & 0.8013 & 0.0854 \\
\hline & $(0.0055)$ & $(0.0507)$ & {$[0.0941]$} \\
\hline \multirow{2}{*}{$\begin{array}{l}\text { Mobility-2 }^{\text {nd }} \text { Born, } \\
\text { Education-Income-Education }\end{array}$} & 0.8151 & 0.5427 & 0.2724 \\
\hline & $(0.0068)$ & $(0.0633)$ & {$[0.0000]$} \\
\hline No. of Observations & 3288 & 62 & \\
\hline
\end{tabular}

Note: Standard Errors are in parenthesis, and p-values are in brackets.

Panels $\mathrm{B}$ and $\mathrm{C}$ reports the same tests but by the gender of the child. It is interesting to note that the decrease in mobility among male children seems to be driven by parental income while that for female children was through parental educational attainment. To the extent that the pattern exhibited by female children parallels that when all children all aggregated together suggests that the decrease in mobility is driven by parental investment in them, which is similar to the insight gained from the regressions of table 5. Panels D and E reports the same results but differentiating the order of birth of the child. Both of the univariate tests suggests little difference between first born child, while there was significant decline in mobility among second born children, results that parallel that observed among families with one children in table 5. Further, notice that the improvement among second born children is derived from both parental education and income, 
nonetheless the small number of observations in the post-OCP state detracts from the finding of significance.

Table 7: Educational mobility by income quartile

\begin{tabular}{l|ccc}
\hline \hline & Pre-OCP Families & Post-OCP Families & Difference \\
\hline $\mathbf{1}^{\text {st }}$ Quartile & 0.8923 & 0.7982 & 0.0942 \\
No. of Observations & $(0.0058)$ & $(0.0454)$ & {$[0.0399]$} \\
\hline $\mathbf{2}^{\text {nd }}$ Quartile & 2833 & 78 & 0.1212 \\
& 0.9276 & 0.8064 & {$[0.0021]$} \\
No. of Observations & $(0.0049)$ & $(0.0391)$ & 0.0363 \\
\hline $\mathbf{3}^{\text {rd }}$ Quartile & 2811 & 102 & {$[0.2238]$} \\
& 0.8922 & 0.8559 & \\
No. of Observations & $(0.0059)$ & $(0.0293)$ & 0.0208 \\
\hline $\mathbf{4}^{\text {th }}$ Quartile & 2767 & 144 & 0.4852 \\
& 0.8504 & 0.8296 & \\
\hline \hline
\end{tabular}

Note: Standard Errors are in parenthesis, and p-values are in brackets.

A closer look at education-education mobility by income quartile is reported in table 7 and the results are somewhat more troublesome with the only significant reductions in the two lowest income quartiles. Thus conditional mobility appears to have diminished predominantly amongst the poor corresponding to diminished life chances of escaping their predicament for the children of poor families.

Contriving a cohesive argument for the cross economy comparison of section 2 with the findings of the last two sections, first note that the cross economy comparisons pertain to the realization variable of real income. In so far as the Economic Reforms expanded the support of income realization, the finding of section 2 is then not surprising, and consequently the outcome observed is not likely a result of the OCP. Secondly, since the finding of section 2 is derived 
from income and not educational attainment, it does not necessarily contradict the finding of sections 3 and 4 . Since the choice of education is conditional to some degree on the income commiserating with that qualification, the increase in the support of income at all levels of educational attainment suggests that using differing variables yields different mobility conclusions. Our choice of educational attainment is motivated by the idea that it is a better measure of the permanent income of an individual. Thus income obscures the fact that there is a fall in mobility among the general populace in post-1979 China, and particularly among the lower strata of the society, highlighting the increased polarization in contemporary urban China. Finally, what may be construed as an effect of the OCP is the increase in investment among female children given the sex ratio in the marriage market created by the binding constraint presented by the OCP.

In the above examination, we have focused on identifiable family relationships, and particularly of families with children between the ages of 19 to 30 and who still remain with the family. In choosing parents who are identified as heads of households, we neglect families embedded in households under other relationships. To the extent that these missing parents or adults within the same age range of parents and children of families under examination likewise exhibit distinct transmission relationships vis-a-vis their children opposing to the reported pattern, our results may be biased. It is not possible for us to identify these relationships since all relationships are linked directly to the head of household, but we can nonetheless examine how different these other individuals are as compared to those included in the sample. This is informative to the extent that if we are willing to assume that the non-identifiable parents are representative of the non-identifiable children, we can see how including these other "families" 
would increase weight towards a particular educational attainment group or socioeconomic group, and how it might possibly affect our conclusion. We create these comparison groups using the year of birth of the individuals and their relationships to the head of household, and examined if their densities are similar to those used, as well as examine the stochastic dominance relationships against the sample ${ }^{11}$.

Although there are distinct differences in the densities of those included in the sample and their excluded peers (excluded due to the inability to identify their family relationships directly), in terms of educational attainment the pre-OCP group of parents used first order dominates their peers, while for the post-OCP parents there does not seem to be a distinct first or second order dominance relationship. In terms of income, both pre- and post-OCP parents first order dominate their peers, and this dominance relationship is stronger among post-OCP parents for cutoffs above the $4^{\text {th }}$ decile. On the other hand, while there does not seem to be a distinct dominance relationship between pre-OCP children and their peers, post-OCP children first order dominate their peers not in the sample, suggesting that their inclusion might dilute the educational transmission effect observed. Taken together, the "missing pre-OCP families" would have diminished the intergenerational mobility measure for the pre-OCP cohort, while the "missing post-OCP families" might have accentuated the lack of mobility among the lower socioeconomic groups. None of which would have altered the substance of our conclusion.

\section{Conclusions}

Unlike countries in the west, children do not appear to be over-represented in the poverty group in Urban China in any of the observation periods. What may be interpreted as the child's income

\footnotetext{
${ }^{11}$ The results of been omitted due to space constraints, but are available from the authors upon request.
} 
distribution is seen to stochastically dominate the adult income distribution predominantly based households formed in the pre-1979 environment at the second order. The post-1979 era result is even stronger with the child income distribution first order dominating that of the adult distribution. Indeed it appears that the two policies of 1979 seem to have polarized (i.e. widened the gap between) child and adult income distributions ${ }^{12}$. Thus the general dominance relationship between child and adult income distributions does not appear to be a result of the $\mathrm{OCP}^{13}$ though not surprisingly it does appear to have precipitated an improvement in the wellbeing of children relative to the adult population.

With respect to mobility, the increased intensity of investment in child quality brought about by the OCP and the Economic Reforms has reinforced the link between parent and child quality and reduced generational mobility as a result. This is contrary to the results found for the U.S. for example where generational mobility has increased over the last part of the $20^{\text {th }}$ Century (Anderson and Leo (2006a)). When viewed by income quartile, increases in immobility are found to be more prevalent in the lower income quartiles reinforcing notions of "Dynastic Poverty" discussed in Kanbur and Stiglitz (1986).

\footnotetext{
${ }^{12}$ On the other hand policies pursued in Canada, the UK and India, our comparator societies, appeared to have narrowed the gap between the child and adult income distributions where generally the adult income distribution dominates that of the children.

${ }^{13}$ It could well be a consequence of the nature of household formation and the extended family found in China (however it does not seem to be the case in Urban India where similar extended family arrangements prevail) together with higher income elasticities of demand for children than are prevalent in the west, all of which is the subject of ongoing research.
} 


\section{References}

Anderson G.J. (2004) “Toward an Empirical Analysis of Polarization” Journal of Econometrics $1221-26$.

Anderson G., and Y. Ge (2004) "Do Economic Reforms Accelerate Urban Growth: The Case of China" (2004) Urban Studies 11 2197-2210.

Anderson G., and Y. Ge (2005) "The Distribution of Chinese City Sizes" Journal of Regional Science and Urban Economics

Anderson G.J., Ge Y. and T.W. Leo (2008) "Distributional Overlap: Simple, Multivariate, Parametric and Non-Parametric Tests for Alienation, Convergence and General Distributional Difference Issues", Mimeo University of Toronto, Department of Economics.

Anderson G.J. and T.W. Leo (2006) "Indices and Tests for Matching and Mobility Theories: A Note" Mimeo University of Toronto, Department of Economics.

Anderson G.J. and T.W. Leo (2006a) "Evaluating Equal Opportunity Policies: The Impact of Changes in Child Custody Law and Practice on Generational Mobility in the United States." Mimeo University of Toronto, Department of Economics.

Anderson G.J. and T.W. Leo (2007) "Family Formation and the One Child Policy in Urban China" Mimeo University of Toronto, Department of Economics.

Anderson G.J, Leo T.W. and R. Muelhaupt (2008) "Qualified Equal Opportunity and Conditional Mobility: The case of Gender Equity in Educational Attainment in Canada." Mimeo University of Toronto, Department of Economics.

Atkinson A.B. (1987) “On the Measurement of Poverty” Econometrica 55, 749-764.

Bartholemew D.J. (1982) Stochastic Models for Social Processes. $3^{\text {rd }}$ ed., Wiley New York.

Bjorklund A., T. Eriksson, M. Jantti, O. Raaum and E. Osterbacka (2004) "Family Structure and Labor Market Success: the Influence of Siblings and |Birth Order on the Earnings of Young Adults in Norway, Finland and Sweden. Chapter 9 in Generational Income Mobility in North America and Europe Miles Corak ed. Cambridge

Blanden, J., A. Goodman, P. Gregg and S. Machin (2004) "Changes in Intergenerational Mobility in Britain" chapter 6 of M. Corak (editor) Generational Income Mobility in North America and Europe. Cambridge

Brady D.S. and H.A. Barber (1948) "The Pattern of Food Expenditures" Review of Economics and Statistics 30 198-206. 
Brandt L and C Holz (2006) "Spatial Price Differences in China: Estimates and Implications." Economic Development and Cultural Change, 55 43-86

Brewer M., Brown J. and H. Sutherland (2006) "Micro-simulating Child Poverty in 2010 and 2020" Joseph Rowntree Foundation.

Brewer M., Goodman A., Shaw J., and L. Sibieta (2006a) Poverty and Inequality in Britain: 2006. The Institute For Fiscal Studies.

Browning M., Chiappori P.A., and A Lewbel (2006) "Estimating Consumption Economies of Scale, Adult Equivalence Scales and Household Bargaining Power: Oxford University Economics Department Discussion Paper ISSN 1471-0498.

Chakravarty S.R. (1995) "A Note on the Measurement of Mobility” Economics Letters 4833 36.

Clark, C. (1961) "The Greatest of a Finite Set of Random Variables" Operations Research 9 $145-162$.

Corak M. (2004) Generational Income Mobility in North America and Europe Cambridge University Press.

Daganzo C. (1980) Multinomial Probit. New York; Academic.

Davidson, R and J-Y Duclos (2000) "Statistical Inference for Stochastic Dominance and for the Measurement of Poverty and Inequality" Econometrica 68, 2000, 1435-1464

Deaton A.S. (1981) "Theoretical and Empirical Approaches to Consumer Demand Under Rationing." In Essays in the Theory and Measurement of Consumer Behaviour: In Honour of Sir Richard Stone. A.S. Deaton ed. Cambridge University Press.

Dworkin R. (1981) "What is Equality? Part 2: Equality of Resources" Philosophy and Public Affairs 10 283-345.

Foster J.E. and A.F. Shorrocks (1988) "Poverty Orderings" Econometrica 56 pp.173-177.

Hart, P.E. (1983) "The size mobility of Earnings" Oxford Bulletin Of Economics and Statistics 45 181-193.

Kanbur S.M.R. and J.E. Stiglitz (1986) Intergenerational Mobility and Dynastic Inequality Woodrow Wilson Discussion Paper No 111 Princeton University.

Kantarevic J. and S. Mechoulan, (2006) "Birth Order, Educational Attainment and Earnings: an Investigation using the PSID”, Journal of Human Resources 41 (4) 755-777. 
Maasoumi E. (1986) "The Measurement and Decomposition of Earnings Mobility" Econometrica 54 991-997

Maasoumi E. (1996) "On Mobility" in D. Giles and A. Ullah (eds) Handbook of Applied Economic Statistics, Marcel Dekker.

Maasoumi E. and S. Zandvakili (1996) "A Class of Generalized Measures of Mobility with Applications" Economics Letters 22, 97-102.

Neary J.P. and K.W.S. Roberts (1980) "The Theory of Household Behaviour Under Rationing" European Economic Review 13 25-42.

Peters M. and A. Siow (2002) "Competing Pre-Marital Investments" Journal of Political Economy, June 2002, 592-608.

Roemer J.E. (2002) "Equal opportunity: A Progress Report" Social Choice and Welfare. 19 455-471.

Shorrocks A.F. (1976) "Income Mobility and the Markov Assumption" Economic Journal 86 566-577.

Shorrocks A.F. (1978) “The Measurement of Mobility” Econometrica 46 1013-1024.

Shorrocks A.F. and J Foster (1992) "On the Hart Measure of Income Mobility" in Industrial Concentration and Income Inequality: Festschrift for Peter Hart.

Wolak F.A. (1989) "Testing Inequality Constraints in Linear Econometric Models" Journal of Econometrics 41 205-235. 


\section{Appendix}

\section{A.1. Dominance Relations and Statistics}

The following table reports the child and adult proportions at income deciles, differences and standard deviations. For "child dominance" no differences must be significantly positive with at least one significantly negative. All calculations and standard errors are based upon the formulae from Davidson and Duclos (2000) for non-independent samples (see also Anderson (2004).

\begin{tabular}{|c|c|c|c|c|c|c|c|c|c|}
\hline \multicolumn{10}{|c|}{ Panel A: Child and Adult proportions at income deciles, Urban China } \\
\hline Case & Decile & Cut-off & Chil & Share & Adu & Share & \multicolumn{2}{|c|}{ Difference } & Diff Std Error \\
\hline \multirow{9}{*}{$\begin{array}{l}\text { China } \\
2001 \\
N_{c}=10569 \\
N_{a}=3936\end{array}$} & 1 & 0.8603 & \multicolumn{2}{|c|}{0.0880} & \multicolumn{2}{|c|}{0.1319} & \multicolumn{2}{|c|}{-0.0439} & 0.0105 \\
\hline & 2 & 0.9088 & \multicolumn{2}{|c|}{0.1825} & \multicolumn{2}{|c|}{0.2477} & & 652 & 0.0136 \\
\hline & 3 & 0.9506 & \multicolumn{2}{|c|}{0.2799} & \multicolumn{2}{|c|}{0.3537} & \multicolumn{2}{|c|}{$\begin{array}{l}-0.0652 \\
-0.0738\end{array}$} & 0.0152 \\
\hline & 4 & 0.9848 & \multicolumn{2}{|c|}{0.3792} & \multicolumn{2}{|c|}{0.4558} & \multicolumn{2}{|c|}{-0.0766} & 0.0160 \\
\hline & 5 & 1.0113 & \multicolumn{2}{|c|}{0.4837} & \multicolumn{2}{|c|}{0.5434} & \multicolumn{2}{|c|}{-0.0598} & 0.0161 \\
\hline & 6 & 1.0339 & \multicolumn{2}{|c|}{0.5913} & \multicolumn{2}{|c|}{0.6235} & \multicolumn{2}{|c|}{-0.0322} & 0.0157 \\
\hline & 7 & 1.0555 & \multicolumn{2}{|c|}{0.6932} & \multicolumn{2}{|c|}{0.7180} & \multicolumn{2}{|c|}{-0.0248} & 0.0147 \\
\hline & 8 & 1.0831 & \multicolumn{2}{|c|}{0.7911} & & 239 & 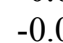 & 328 & 0.0125 \\
\hline & 9 & 1.1236 & & 3916 & & 223 & -0.0 & 307 & 0.0091 \\
\hline & 1 & 0.8860 & & 765 & & 389 & -0.0 & 624 & 0.0089 \\
\hline & 2 & 0.9402 & & 1760 & & 406 & -0.0 & 646 & 0.0114 \\
\hline & 3 & 0.9824 & & 2772 & & 375 & & 603 & 0.0129 \\
\hline China & 4 & 1.0131 & & 3770 & & 378 & & 608 & 0.0137 \\
\hline 1987 & 5 & 1.0394 & & 4804 & & 352 & & 548 & 0.0139 \\
\hline$N_{c}=3387$ & 6 & 1.0645 & & 5890 & & 176 & & 286 & 0.0136 \\
\hline$N_{a}=2074$ & 7 & 1.0906 & & 6994 & & 049 & -0.0 & 056 & 0.0127 \\
\hline & 8 & 1.1192 & & 3087 & & 869 & & 218 & 0.0112 \\
\hline & 9 & 1.1633 & & 114 & & 809 & & 305 & 0.0086 \\
\hline & Panel I & Child an & Adu & t propo & tions & at incol & ne de & ciles, & Canada \\
\hline Case & Decile & Child S & nare & Adult & hare & Differ & nce & Diff $S$ & td Error \\
\hline Canada & 1 & 0.11 & & 0.09 & & 0.01 & & 0.0 & 037 \\
\hline 2004 & 2 & 0.20 & & 0.20 & & -0.0 & & & 049 \\
\hline$N_{c}=10569$ & 3 & 0.30 & & 0.29 & & 0.00 & & & 056 \\
\hline$N_{a}=3936$ & 4 & 0.41 & & 0.39 & & 0.01 & & & 060 \\
\hline & 5 & 0.52 & & $0.4 \mathrm{C}$ & & 0.03 & & 0.0 & 061 \\
\hline & 6 & 0.63 & & $0.5 \mathrm{~s}$ & & 0.04 & & 0.0 & 059 \\
\hline & 7 & 0.74 & & 0.68 & & 0.05 & & 0.0 & 054 \\
\hline & 8 & 0.85 & & 0.80 & & 0.05 & & & 044 \\
\hline & 9 & 0.92 & & 0.85 & & 0.03 & & 0.0 & 034 \\
\hline Canada & 1 & 0.12 & & 0.09 & & 0.03 & & 0.0 & 033 \\
\hline 1997 & 2 & 0.22 & & 0.19 & & 0.03 & & 0.0 & 042 \\
\hline $\mathbf{N}_{\mathrm{c}}=\mathbf{3 3 8 7}$ & 3 & 0.33 & & 0.28 & & 0.04 & & 0.0 & 048 \\
\hline$N_{a}=2074$ & 4 & 0.44 & & 0.38 & & 0.05 & & 0.0 & 051 \\
\hline & 5 & 0.54 & & 0.48 & & 0.06 & & 0.0 & 051 \\
\hline & 6 & 0.65 & & 0.58 & & 0.07 & & 0.0 & 049 \\
\hline & 7 & 0.75 & & 0.67 & & 0.07 & & & 045 \\
\hline & 8 & 0.85 & & 0.78 & & 0.06 & & & 038 \\
\hline & 9 & 0.93 & & 0.85 & & 0.04 & & & 027 \\
\hline
\end{tabular}




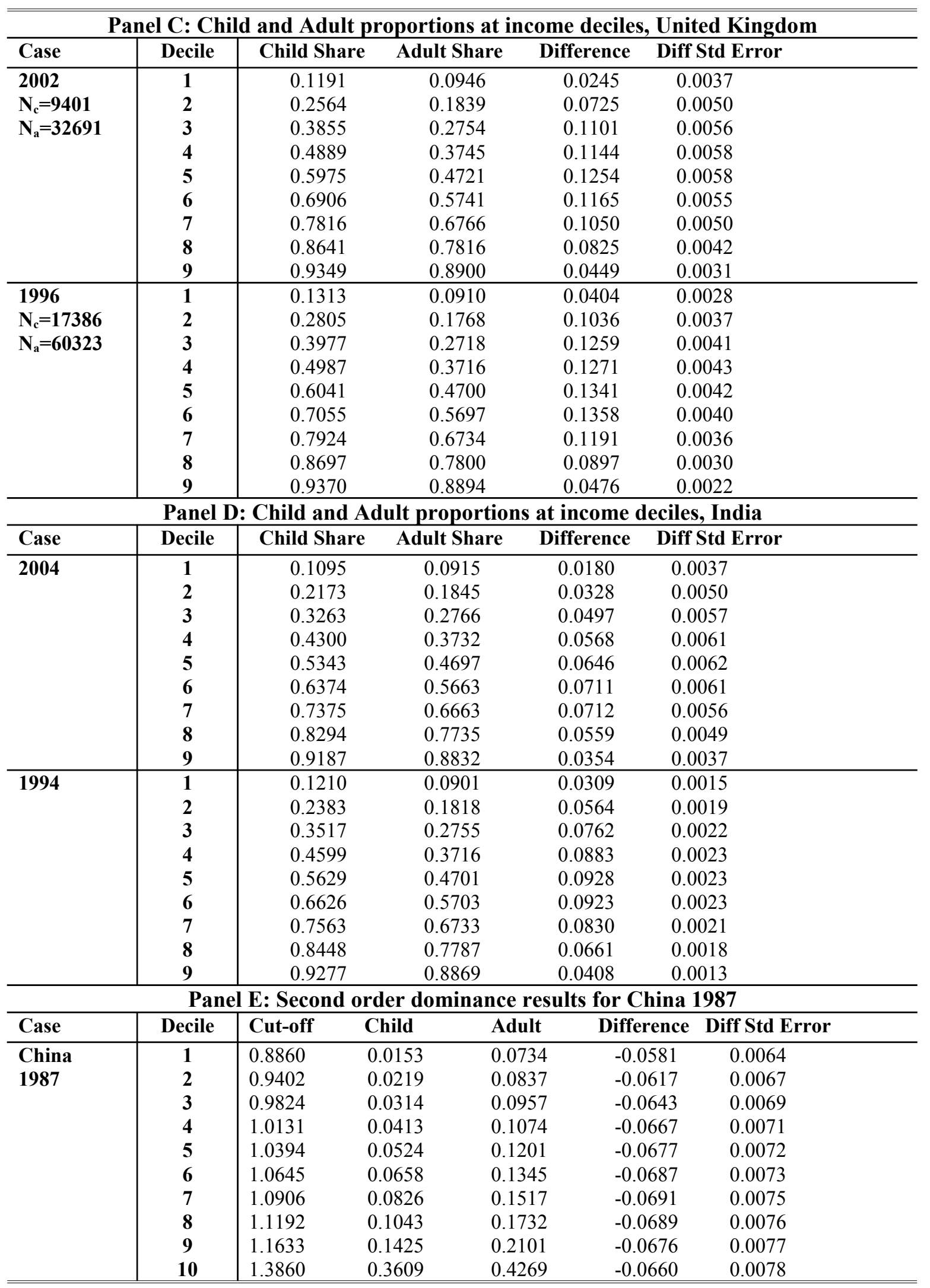

